\title{
Nefando de Mónica Ojeda Franco. La infancia tiene una voz baja y un vocabulario impreciso: Escribir, perturbar, decir lo indecible
}

\author{
Nefando, by Mónica Ojeda Franco. \\ Childhood's voice is low and its vocabulary, imprecise: \\ Writing, disturbing, saying the unspeakable \\ Alicia Ortega Caicedo \\ Universidad Andina Simón Bolívar, Sede Ecuador
}

DOI: https://doi.org/10.32719/13900102.2018.44.10

Fecha de recepción: 11 enero 2018 Fecha de aceptación: 16 marzo 2018 
La literatura no puede distraerse con elefantes, tiene que apartarlos y ver al acróbata caido, interesarse por su sufrimiento, por la mueca de dolor con la que lo llevan tras bambalinas porque desentona, porque rompe la armonia, porque obsceniza el espectáculo.

En lo probibido se acurruca, temerosa, la sintaxis social. Las palabras no pueden decir que las palabras no pueden decir.

Nefando, Mónica Ojeda

\section{RESUMEN}

La novela de la escritora ecuatoriana Mónica Ojeda, Nefando (2016), centra el interés de una reflexión acerca de las posibilidades de nombrar y narrar experiencias corporales extremas, cuando de una infancia vulnerada se trata. Interesa también reconocer en la novela una línea de pensamiento en torno a la escritura, la violencia y el dolor de los demás. Escribir, perturbar, renombrar, obscenizar son verbos que coinciden en el horizonte de un campo semántico que busca poner en crisis nociones asumidas respecto a la infancia y la familia. Cómo decir lo que no puede decirse es una pregunta que activa la escritura de Nefando.

Palabras clave: Novela ecuatoriana, Mónica Ojeda, Nefando, violencia y escritura, infancia vulnerada.

\section{ABSTRACT}

The novel by Ecuadorian writer Mónica Ojeda, Nefando (2016), centers its interest in reflecting upon the possibilities of naming and narrating extreme corporal experiences when it comes to a damaged childhood. It is also interesting to recognize a line of thought around childhood in the novel, as well as violence and pain suffered by others. Writing, disturbing, showing the obscene are verbs that meet in the horizon of a semantic field that seeks to put in crisis the assumptions adopted with respect to childhood and family. The writing of Nefando is activated by the question of how to say what cannot be said. KEYWORDS: Ecuador, novel, Mónica Ojeda, violence and writing, damaged childhood.

En NEFANDo (2016), de Mónica Ojeda -Guayaquil, 1988-, Nefando. Viaje a las entrañas de una habitación es el nombre de un videojuego en línea, que rápidamente fue eliminado de la red por la policía a causa de su polémico contenido ligado a la pederastia, el incesto, la violencia, el abuso infantil. La novela se centra alrededor de seis jóvenes que compartieron el departamento en donde fue creado el videojuego: los hermanos Terán (Irene, Emilio, Cecilia), tres universitarios ecuatorianos que inventaron el juego, dos mexicanos -Kiki Ortega, becaria y escritora, e 
Iván Herrera, estudiante de una maestría en escritura creativa- y el Cuco Martínez, programador español y hacker. Una voz anónima, interesada en recomponer los sucesos relacionados con la creación del videojuego, entrevista a quienes convivieron con los hermanos. Fragmentos de las entrevistas, una novela pornoerótica escrita por Kiki, reminiscencias, escritos y dibujos de los hermanos Terán acerca de la infancia compartida y ligada al abuso sexual ejercido por el padre, recopilación de posts y crónicas sobre el videojuego, códigos de programación, son elementos de procedencia disímiles que concurren en una novela de estructura fragmentada e híbrida (cercana a la forma coral y al mosaico). El recurso testimonial, el afán periodístico, la parodia pornográfica, el carácter metaficcional, las resonancias intertextuales en el continuo diálogo con el cine y la literatura, el espacio virtual como referente y escenario paralelo, ${ }^{1}$ provocan el efecto de una escritura que socava su estatuto ficcional en la explícita indagación en torno a un lenguaje capaz de dar forma y nombre a experiencias corporales extremas: experiencias que, anudadas a la crueldad y la violencia, suelen quedar agazapadas en el silencio, el balbuceo, el grito. En esta línea de reflexión, Mónica Ojeda ha señalado que

la novela trabaja sobre el daño a los cuerpos y sobre los conflictos que tienen que ver con la experiencia corporal. Todos los personajes de Nefando han tenido experiencias de daños psicológicos y físicos en su pasado. Lo han ejercido o lo han recibido. Son personajes que están lidiando con algo que les ha dejado huella. El abuso sexual es un tema tabú que incomoda y que todo el mundo prefiere evitar (en Flores 2017).

La novela inicia con un texto que remite a la voz de Kiki en su devenir escritora: la escritura alterna, en líneas cursivas y en primera persona, el proceso imaginativo que concibe una novela pornográfica alrededor de la sexualidad de tres adolescentes y el deseo de Kiki por explorar los límites y alcances del lenguaje. A la vez leemos, de manera intercalada y en tercera persona, la descripción del entorno espacial y biográfico de la joven

1. En una entrevista, Ojeda advierte: “La 'deep web' es un espacio virtual en donde proliferan todo tipo de expresiones, pero lo que me interesaba era cómo es también un agujero negro en donde el daño que se le hace a algunas personas se extiende. Allí hay hackers, foros de pedófilos en donde circula pornografía infantil, torturas a animales, venta de armas y de droga... hasta se puede contratar a sicarios. Es un lugar en donde algunas personas se esconden y, a la vez, se desnudan ante otros" (en Castro 2016). 
aprendiz. Ambas líneas narrativas coinciden en lo que podemos reconocer una suerte de arte poética, una clave de lectura al momento de incursionar en Nefando: "¿Qué tan difícil podía ser escribir una novela? [...] Una novela sobre la crueldad, una novela destinada a perturbar" (Ojeda 2016, 8; cursivas en el original). "Perturbar" es un verbo que, en la repetida exploración de sus múltiples definiciones, activa en la lectura un conjunto de ideas que se revelan matriz de escritura: poner en movimiento lo que parece estancado, escribir con el cuerpo hundido en una ciénaga, hacer escuchar la vida de afuera, mostrar el dolor agazapado, entender la sexualidad a través del horror y de la muerte, desactivar la indiferencia ante el dolor de los demás, explorar lo inquietante, derrotar el silencio, decir lo indecible, romper el guión establecido, articular lo revulsivo, rememorar la infancia vulnerada. Los capítulos que corresponden a la voz de Kiki dotan a la novela de una significativa densidad metaliteraria, que pone en escena el proceso de escritura y la interroga. En esta primera entrada que abre la novela, la joven becaria rememora un episodio infantil en el circo: durante la función, un acróbata se cae de la cuerda floja, se estrella contra el suelo y uno de los huesos de la pierna rota se sale de su sitio y salpica de sangre todo el entorno. La gente rápidamente se olvida del acróbata accidentado cuando entran los elefantes a la pista, y el espectáculo continúa. Kiki recuerda ser la única que no quería que los elefantes la distrajeran del hombre caído y desangrado. La literatura, piensa, debe cumplir esa función: explorar lo inquietante, decir lo que no puede decirse, fijar la atención en la carne rota que "obsceniza el espectáculo": "La literatura no puede distraerse con elefantes, tiene que apartarlos y ver al acróbata caído” (14). La literatura es asumida como una forma de mirar, como dispositivo que permite ver la sombra del otro al lado de una misma, allí en donde cabe la pregunta por la "caja de empatía” para conectarse con el dolor y la alegría de los otros.

Los personajes de la novela son lectores (saben que "para leer bien hay que leer mal"), estudiantes de posgrado, escritores, artistas, que discuten y reflexionan sobre los procesos creativos, la escritura, la literatura, el lenguaje, el espacio virtual. Los diálogos y líneas de pensamiento que se generan alrededor de estos motivos dotan al texto de un carácter metaficcional. Nefando configura una escritura que no deja de pensarse, en la búsqueda de un lenguaje que pueda expresar el dolor padecido por cuerpos que han sido cruelmente lastimados: un lenguaje capaz de hablar 
de la carne rota, de la perversión, de la sombra que anida en el interior humano, de narrar el horror propio. La pregunta por la representación de la violencia se actualiza en el horizonte de un escenario en donde coinciden el mal, la abyección, lo obsceno: "Escribir es estar en un lugar de tensión y de incomodidad" (32), sugiere Iván. La búsqueda que plantean los personajes en sus proyectos de escritura, así como la referencia a sus historias de vida, sitúan el debate en torno a la violencia, el dolor carnal, el placer, la pornografía infantil, el amor, la sumisión, el maltrato animal, el sacrificio. Esas son las ideas que toman forma en la concepción de Nefando, novela y videojuego: ¿cómo puede un cuerpo torturado/humillado/lesionado producir placer? La pregunta se potencia escandalosamente cuando encarna en cuerpos infantiles heridos por sus propios padres. Porque precisamente son los imaginarios en torno a la familia y la infancia el paradigma que busca quebrar la novela. Lejos de ser un espacio o un período de protección y cobijo resultan la imagen más cercana a la idea de abuso, fragilidad y desamparo: "la infancia, una prueba de resistencia" (54). Son esas las imágenes y los relatos que circulan bien al fondo de la deep web, allí en donde el dolor de unos resulta espectáculo y placer de otros: un lugar en cuyas zonas profundas se configura un mundo alterno y paralelo, que no reinventa nada sino que concentra todos los males sociales del mundo físico y "real”. La única diferencia, afirma el Cuco, "es que en el cibermundo todos nos atrevemos, al menos una vez, a ser criminales o moralmente incorrectos" (70).

Algunos capítulos de la novela reconstruyen la infancia de los Terán y la enrarecida figura paterna que abusa de ellos. El recuerdo de una serie de sucesos revela la ominosa presencia de un padre que somete a los niños a situaciones de violencia extrema: tortura, abuso sexual, dolor físico, órdenes humillantes, todas escenas que transcurren frente a una cámara que los filma. El relato de esas vivencias se articula, simultáneamente, con una reflexión en torno al decir y al saber:

El problema era que, por mucho que lo intentara, la hija no podría formular ni articular la bruma que se arremolinaba en una esquina de su relación con el padre. Había algo contaminante, algo que no era tangible ni visible, algo que percibía pero que no podía decir. [...] Cuando pensaba demasiado en lo que no podía decir, en todo aquello que no sabía contar, su convicción se volvía menos árida y las intenciones de su padre más oscuras. [...] Estaba segura de que cuando fuera mayor podría decir todo lo que percibía, nombrarlo con las palabras adecuadas, hacer una verdad convincente, 
darle cierto sentido al caos. [...] Quería saber por qué se sentía despojada de su identidad cada vez que se quedaba sola con el padre (Ojeda 2016, 74, 76, 77).

Si la infancia expone su vulnerabilidad en la dificultad de nombrar la intolerable realidad, más aún cuando aquello que busca ser contado no tiene cabida en ningún concepto articulable, Nefando no es sino la puesta en lenguaje de una experiencia ininteligible y abyecta - de allí la necesidad de "escribir(se) para entender(se)" que experimentan los hermanos en la vida adulta. Articular el saber, con el decir, el ver y el hacer, en términos de Rancière (2010), favorece una deriva emancipatoria así como la posibilidad de resistir al despojamiento. Decir lo que se sabe y se ve, así como saber lo que se hace, desactiva la vertical oposición entre actor y espectador, entre torturador y víctima: “Alguna vez la hija menor intentó poner en palabras su disgusto hacia la cámara y las manos cayosas que la tocaban por debajo de la ropa, pero nadie la escuchó. La infancia tenía una voz baja y un vocabulario impreciso" (Ojeda, 77). Rita Segato ha señalado que la "violación cruenta" -aquella cometida por personas desconocidas y anónimas, en la que la persuasión cumple un papel menor- es el tipo de delito con menor representación cuantitativa entre las formas de violencia sexual. La violencia doméstica y los abusos cometidos en la intimidad del hogar, observa Segato, son las formas más comunes y frecuentes de esos delitos. Esa "violencia invisible", practicada contra la mujer (podemos añadir, contra los niños), en el ámbito de las relaciones familiares, se asemeja a una situación de "violencia estructural", "que se reproduce con cierto automatismo, con invisibilidad y con inercia" (Segato 2003, 113). Esta violencia invisibilizada suele estar entremezclada con ritos, códigos, costumbres, hábitos que han sido normalizados y naturalizados en casa. La antropóloga y feminista argentina considera que uno de los aspectos que caracterizan este tipo de violencia es "la falta de nombres u otras formas de designación e identificación de la conducta, que resulta en la casi imposibilidad de señalarla y denunciarla e impide así a sus víctimas defenderse y buscar ayuda" (115). Así pensado, el tema de la violencia remite, entre otros aspectos, a una pregunta por el lenguaje: cómo se habla de la violencia, cómo se nombra la conducta violenta cuando ella se produce entremezclada en una trama de relaciones cotidianas, afectivas y familiares. Más aún, cuando en la infancia se desconocen las palabras y los nombres adecuados para nombrarla. Esa forma de silencio podemos reconocer en 
una frase de Cecilia, que el Cuco Martínez rememora en la entrevista final que cierra la novela: "Me dijo algo así como que el silencio no era la ausencia del habla ni de la escritura, sino el instante en el que las palabras perdían todo su sentido" (Ojeda, 199).

En las reflexiones de Kiki se repite la idea que el dolor es incomunicable e intransferible, no así su experiencia puesto que existe un léxico para describirlo, uno que remite al exceso ligado a la corporalidad: "nunca nuestro cuerpo es más nuestro que cuando nos duele" (81). Cómo decir el dolor es una pregunta recurrente que entreteje los relatos y pone en diálogo las diferentes voces narrativas. Pregunta para nada retórica puesto que su riqueza metaficcional ancla en dicha reflexión. Más aún cuando lo que está en juego es una infancia quebrada que carece, porque desconoce, de las palabras necesarias para nombrar esa vivencia. Se trata de una pregunta que con fuerza sostiene la voz de Kiki: "Escribo a ciegas, pensó, siento la pulsión de decir lo que no sé decir. Un lenguaje pornográfico podía ser el que desocultara la palabra, el que la arrancara de sus ropajes y violentara su normatividad" (94; cursivas en el original). No deja Kiki de preguntarse por el dolor y la escritura en relación a la infancia como período de peligro y de fragilidad. Recuerda ella haber sido mortificada en la niñez por escribir cuentos pornográficos, "sucios y despreciables": castigada, encerrada en un baúl, reconoció que la valentía es necesaria para "escribir mal”. Tiempo después descubrirá que "la irreverencia se parece a la escritura que bebe de los tropiezos” (138). Escribir mal y retener la fuerza para lidiar con la palabra prohibida devienen aprendizajes adquiridos en los primeros años a través de una constante prueba de resistencia y exposición del cuerpo que aprendió a sobrevivir su propia infancia.

Los Terán, ya adultos y en Barcelona, colgaron en línea las imágenes de sus propias violaciones, como parte del videojuego que da título a la novela. Se sabe que Nefando causó repugnancia y censura en las redes, frente a lo cual el Cuco Martínez observa que lo que hicieron los hermanos fue "un simple poner en escena lo que está ahí donde es imposible clavar los ojos" (89). Lo que convirtieron en videojuego fueron las grabaciones reales filmadas por el padre: contenido abyecto puesto que, en palabras de Julia Kristeva, tiene que ver con aquello que ha sido arrojado fuera de lo posible, de lo tolerable y de lo pensable: "Aquello que no respeta los límites, los lugares, las reglas. La complicidad, lo ambiguo, lo mixto. El traidor, el mentiroso, el criminal con la conciencia limpia, el 
violador desvergonzado, el asesino que pretende salvar... Todo crimen, porque señala la fragilidad de la ley, es abyecto" (Kristeva 2013, 11). Son aún más abyectas, desarrolla Kristeva, aquellas acciones que intensifican la exhibición de la fragilidad. El daño causado a los hermanos en la infancia entra en el ámbito de lo turbio y de lo abyecto: “crecimos y papá nos disparó de muchas maneras” (Ojeda, 124). La detallada evocación de Emilio deja ver eso que George Bataille (1959) ha denominado expresión del Mal puro, uno que no persigue ningún beneficio ni bien material, sino el solo goce de quien lo ejecuta. Si frente a la abyección el sentido está ausente, el sujeto que ha padecido el horror enfrenta la pregunta acerca de cómo decir lo que no se ha dicho nunca: "ensuciar(se) en el lenguaje", desocultar la palabra, se imponen como actos de liberación.

Los Terán inventaron el videojuego como espacio para dar cabida a lo innombrable y exponerlo públicamente: "A veces tenemos que hacer y dejar que lo hecho pronuncie nuestro vértigo" (Ojeda, 107), sugiere Emilio como esperanzadora apuesta para reconciliar el decir con el hacer, cuando de narrar el daño se trata. En función de ello, Cecilia dibuja lo que no puede decirse, y Emilio intenta que las palabras tengan un sentido renovado: "Intento hacer mi propia dicción del mundo. Cecilia, en cambio, despeña los significados. Su silencio es la carne de mi miedo" (131). Los hermanos subieron el videojuego a internet en un momento que antecede al presente narrativo, pero que configura la trama anecdótica, conduce las entrevistas, anima los diálogos, reflexiones y recuerdos de los personajes. Cómo decir el dolor es la manifiesta pregunta que organiza la novela, una pregunta que empata con una polémica de antigua genealogía en torno a "lo irrepresentable" y "lo indecible". Colgar los videos en formato de juego en línea puede ser leído como una investidura simbólica de liberación, en el sentido de estar en capacidad de poder decir/poder contar, en la perspectiva de generar un precario ordenamiento del caos. Inventar una "dicción propia del mundo" permite a los hermanos lidiar con el propio pasado y, más importante todavía, no considerarse víctimas. Desde otra línea de pensamiento, en el marco de una reflexión sobre el testigo/ superviviente del campo de concentración, Giorgio Agamben problematiza la idea acerca de la naturaleza indecible de una experiencia atroz. El filósofo italiano se pregunta ¿por qué conferir al exterminio el prestigio de la mística? "Observar el silencio religioso" es una práctica de adoración a Dios, que es indecible e inenarrable. Callar la violencia equivale a "adorarla 
en silencio" (Agamben 2002). Podemos pensar que los hermanos Terán mantienen, en calidad de supervivientes, fija su mirada en lo inenarrable como experiencia fundante.

La escritura de Nefando da cuenta de un intenso y cuidado trabajo por encontrar las palabras para decir lo que usualmente queda excluido del lenguaje, para recomponer el sentido que ha sido arrebatado y despojado. Susan Sontag, en su reconocido libro Ante el dolor de los demás (Sontag 2004), plantea no dejar de explorar y mirar de frente la atrocidad. Aunque la iconografía del sufrimiento es de viejo linaje, y ser espectador de calamidades es una experiencia intrínseca de la modernidad, importa no dejar de preguntarse qué hacer con las emociones que el sufrimiento del otro ha despertado en nosotros. "El dolor es incomunicable, sí, pero su experiencia no: existe un léxico para describirlo" (Ojeda, 80), sugiere Kiki. En la búsqueda del léxico para describirlo se inscribe Nefando. Quiero cerrar con la anécdota que introduce Kiki casi al inicio de la novela, a propósito del acróbata caído y los elefantes distractores. Ese fue, recuerda ella, su primer contacto con la indiferencia de los demás. Nefando es eso: una exploración en el lenguaje que no renuncia al silencio ni a la indiferencia, en el esfuerzo por crear uno capaz de asir lo abyecto, decir el dolor, derrocar el silencio. *

\section{Bibliografía}

Agamben, Giorgio. 2002. "El testigo". En Lo que queda de Auschwitz. El archivo y el testigo. Homo Sacer III. Valencia: Pre-Textos.

Bataille, George. 1959. La literatura y el mal. Madrid: Taurus.

Castro, Anton. 2016. "La literatura es un cigarrillo que quema la mano". Entrevista con Mónica Ojeda. Disponible en ‘http://www.heraldo.es/noticias/ocio-cultura/10/14/literatura-cigarrillo-que-quema-mano-1112740-1361024. html.

Flores, Gabriel. 2017. "Hay que llevar la escritura a la zona del tabú". En El Comercio. Entrevista con Mónica Ojeda. Disponible en 〈http://www.elcomercio.com/tendencias/monicaojeda-escritura-tabu-literatura-caninos.html. 19 octubre.

Kristeva, Julia. 2013. Poderes de la perversión. México: Siglo XXI.

Ojeda, Mónica. 2016. Nefando. Barcelona: Candaya.

Rancière, Jacques. 2010. El espectador emancipado. Buenos Aires: Manantial. 
KİPUS 44, julio-diciembre 2018

Segato, Rita. 2003. "La argamasa jerárquica: violencia moral, reproducción del mundo y la eficacia simbólica del derecho". En Las estructuras elementales de la violencia. Ensayos sobre género entre la antropología, el psicoanálisis y los derechos humanos. Bernal: Universidad Nacional de Quilmes. 107-128.

Sontag, Susan. 2004. Ante el dolor de los demás. Bogotá: Alfaguara. 